\title{
Leadership effectiveness in Higher Education: Managerial self-perceptions versus perceptions of others
}

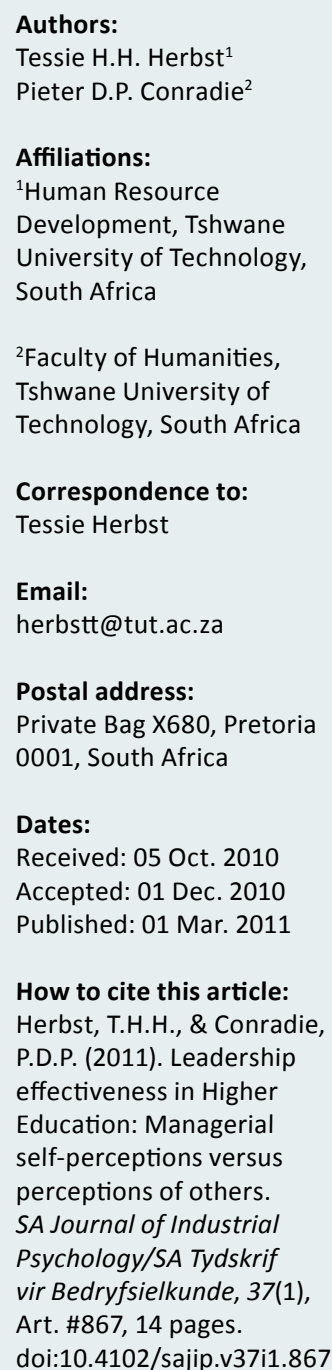

doi:10.4102/sajip.v37i1.867

\begin{abstract}
Orientation: The study reported here explores the relationship between managerial selfperceptions and perceptions of others (the manager's direct supervisor, peers and subordinates) with regard to leadership effectiveness (LE) in a group of managers in the context of a South African university undergoing a merging process.
\end{abstract}

Research purpose: The purpose of this study was to investigate the prevalence of selfperception accuracy amongst the managers and to explore the patterns of interaction between self-perception accuracy (regarding their leadership behaviour) and perceived transformational leadership behaviour (as measured by composite 'other'-ratings)

Motivation of the study: Research has shown that managers in various work environments typically overestimate their own level of competence and that this could impact on the effectiveness of their leadership behaviour. This phenomenon has however not yet been researched in the context of South African higher education institutions.

Research design, approach and method: A quantitative cross-sectional study of the relationship between self-perception accuracy and leadership effectiveness was conducted amongst the total population $(N=204)$ of staff members in management positions. The response rate was $67 \%$ and the realised sample consisted of 137 managers. Leadership behaviour was measured by means of behavioural ratings on the following five dimensions of the Leadership Practices Inventory (LPI): 'Challenging the process', 'Inspiring a shared vision', 'Enabling others to act', 'Modelling the way' and 'Encouraging the heart'.

Main findings: Statistically significant discrepancies were found between self- and observer ratings on all five leadership dimensions, indicating a probable overestimation of their own capabilities. Results further provide evidence that perceived leadership effectiveness on three of the five transformational leadership practices varied as a function of the self-perceptions of managers.

Practical/managerial implications: Managerial development practices should sensitise managers to what is essentially introspective and provide opportunities for them to reflect upon and question their leadership practices.

Contribution/value-add: A challenge for higher education is to embark on feedback intensive leadership development processes that provide participants with comprehensive feedback in a supportive environment.

\section{Introduction}

It is generally accepted that effective leadership is an essential element of positive social change in any institution. It also seems evident that no society can continue to grow and develop without it and that no institution can thrive where it is unavailable. However, these statements raise a number of questions such as:

- Whose perceptions of effective leadership is applicable here - the perceptions of those in leadership positions themselves, or the perceptions of others?

- What is likely to happen in the case of conflicting perceptions of leadership effectiveness?

This study explores this issue by focusing on the relationship between self-ratings and otherratings of managerial leadership within a particular context, namely a South African higher education institution that is in the throes of a radical merging process and on the prevalence of self-perception accuracy amongst the managers of that institution. 


\section{Background to the study}

Higher education in South Africa, like in many countries in Europe and elsewhere, is facing major transformation challenges that require extraordinary leadership (Bosch, 2006; Brennan, 2005; Jansen, 2004; Hargreaves \& Fink, 2003; Van Ameijde, Nelson, Billsberry \& Meurs, 2009). Since the transition from an apartheid state to a post-apartheid society, higher education systems in South African are in the process of being reformed and restructured (Jansen, Bandi, Chalusu, Lethoko, Sehoole \& Soobrayan, 2002). During this period of great transformation in South African higher education, mergers served as one of the key strategies for the reconfiguration of the landscape of public institutions giving effect to the National Plan for Higher Education of 2001 (CHE, 2004). The fundamental aim of the mergers was:

the creation of a new institution in the full meaning of the term, that is real integration with a new institutional culture and ethos that is more than the sum of the parts.

(DoE, 2002, p.39)

According to Vinger (2008) this was the most ambitious and comprehensive change programme the world has seen in recent times. To provide some perspective on the size of the project, before the merger the 36 higher education institutions consisted of 21 universities and 15 technikons which were reduced to a total of 21 . The higher education institution in which this study was conducted consisted of three different technikons (two of which were previously disadvantaged) which were merged into one university of technology.

Whilst there is a small but growing literature on 'mergers' in higher education (in Becker et al. 2004) very little research has been devoted to the impact of such events on the personal and emotional experiences of the staff undergoing such processes. The existing literature tends to focus on the organisational goals and consequences of mergers and, to a lesser extent, on the fusion of different campus cultures or on what Buono and Bowditch (1989) refer to as the 'human side of mergers and acquisitions'. Transformation of this magnitude might result in confusion, frustration, lack of employee loyalty, clashes in corporate culture, low morale and low motivation for the people involved (Bateman \& Snell, 2002; Becker, et al. 2004). As a result, institutional leadership is confronted with some of its greatest challenges both internally and externally which calls for visionary and transformational leadership. According to Bosch (2006) the success of a merger is greatly dependent on the calibre of management and leadership.

This widespread acceptance of the need for effective leadership to shape institutional transformation in education and elsewhere has led to an extensive rethinking of leadership practices in higher education. Given the view of leadership as a process whereby individuals work together in order to foster change and transformation, new emphasis is now being placed on skills that are tied to relationships and interconnectedness (Martin, 2005). Therefore, to build the leadership capacity necessary for top-quality institutions of higher learning, managers will need to possess good management and technical skills, as well as well-developed social and emotional skills. However, ineffective and inefficient leadership has been identified by various authors as one of the major weaknesses of South African Higher Education, a fact that impedes the transformation agenda (Jansen, 2004; Kotecha, 2003; Seale, 2004). The reason for this lack of leadership capability might be because leadership development has been given little attention by most of our institutions of higher learning. Relatively little attention is being given to the development of those personal qualities that are most likely to be crucial to effective leadership (Astin \& Astin, 2000):

- self-knowledge

- self-awareness

- integrity

- interpersonal skills.

It is clear that the context of leadership is changing and that leadership with the capacity to build relationships, to collaborate and to lead change effectively will be critical to long-term success across domains of expertise and different organisational contexts. Martin (2005) concurs that critical skills for effective leadership in future fall in the category of relationships and collaboration. This view is supported by Van Ameijde, Nelson, Billsberry and Van Meurs (2009) who state that leadership is a shared influence process that 'arises from the interactions of diverse individuals'. A prerequisite for the effective management of these interactions or relationships and fundamental to interpersonal skills is the concept of self-perception accuracy. An accurate selfperception reflects self-awareness (as well as the accurate interpretation) of relationship and interpersonal behaviours. This provides the manager with self-information from various sources which needs to be incorporated into his or her self-evaluation in order to enhance self-perception accuracy (Randall, Ferguson \& Patterson, 2000).

Self-perception accuracy is a critical ingredient for authenticity and in forging a shared purpose for the leadership group by being aware of the competencies and limitations that might impact on the transformation effort (Astin \& Astin, 2000). According to Astin and Astin (2000, p. 73) one 'safe' strategy a leader could adopt in dealing with such a lack of self-perception accuracy is to merely avoid embarking on any attempt at significant institutional transformation. Low self-perception accuracy could also lead to self-delusion where the leader temporarily pacifies followers' need for change by promising what seems like appropriate and reasonable reforms but which are never acted upon because of the leader's lack of conviction or commitment. The most significant long-term consequences of such a response are the erosion of trust in the leader as well as cynicism amongst followers (Astin \& Astin, 2000).

Therefore, for leaders to be able to transform their organisations to become more effective, they first need to understand themselves (Souba, 2006). In this new complex and interdependent work environment, leaders do not only 
need new skills but also have to act differently in order to lead employees resourcefully. This will require leaders to be active, aggressive learners and to develop new leadership skills rapidly and openly (Mclagan, 2002). Therefore, the process of becoming a better leader is fundamentally grounded in personal transformation and self-discovery (Van Velsor \& McCauley, 2004). Self-insight which might result in a more accurate self-perception has been recognised as a basic requirement for conscious, proactive personal change and development, yet it is usually poorly developed (Carlopio, Andrewartha \& Amstrong, 2005). Understanding one's strengths and weaknesses is regarded as essential for conscious personal transformation and development. In other words, we cannot change what we are not consciously aware of (Jokinen, 2005).

In summary, self-perception accuracy seems to be a prerequisite for both individual growth as well as effective organisational transformation. Despite the importance of self-perception accuracy, research has generally found that, typically, managers have a tendency to overestimate their own level of competence (e.g. Alicke, Klotz, Breitenbecher, Yurak \& Vredenburg, 1995; Atkins \& Wood, 2002; Herbst, Maree \& Sibanda, 2006). Research studies (referred to in Atwater, Brett \& Waldman, 2003) found that overraters were poorer performers than under- and in-agreement raters and that the highest performing managers had self- and other ratings that were most similar.

\section{Research objectives}

The purpose of the study was to gain new insights into effective leadership behaviour at South African higher education institutions that are undergoing a process of merging. Stated in more concrete terms, the overall objective was to explore the relationship between managerial selfperceptions and the perceptions of others with regard to leadership effectiveness (LE) in such a South African university context. This was to be achieved by addressing the following three specific research objectives:

- Objective 1: To investigate the prevalence of selfperception accuracy amongst the managers with regard to their leadership effectiveness.

- Objective 2: To investigate the pattern of significant correlations (if any) between self-ratings and otherratings of managerial leadership effectiveness.

- Objective 3: To investigate what types of managerial selfratings (as classified according to the aspect/dimension of leadership behaviour that is involved) contribute most to other-ratings of managerial leadership effectiveness.

It was hoped that this study would yield knowledge of managerial self-perceptions and self-perception accuracy that could be used as a tool in becoming a more effective leader in higher education and that this would support the emerging literature on the importance of self-perception and interpersonal skills for improving leadership effectiveness. The ultimate aim of this study was therefore to gain knowledge of the role of self-perceptions and self-perception accuracy with regard to leadership effectiveness within the context of a merging higher education institution. Furthermore, it was hoped that the results would provide guidance and direction with regard to the design and delivery of management development interventions.

\section{Theoretical basis of the study}

The Kouzes and Posner model of transformational leadership

Leadership is a process that is ultimately concerned with fostering change. Therefore the literature on effective leaders seems to suggest that they tend to be 'transformational' rather than 'transactional' (Harris, Day, Hopkins, Hadfield, Hargreaves \& Chapman, 2003, p. 29). As a result the current emphasis on leadership relates to the ability of a manager to manage and deliver significant organisational transformation (Higgs, 2002). According to Astin and Astin (2000) leaders in higher education should start practicing the principles of transformational leadership. They view transformational leadership as empowering leadership 'because it is predicated on being self-aware, authentic, and empathic and because it develops trust through listening, collaborating, and shaping a common purpose' (p.49).

Transformational leadership includes the following four facets (Bass, 1985, 1998; Bass \& Avolio, 1993):

- idealised influence

- inspirational motivation

- intellectual stimulation

- individualised consideration.

Apart from being linked with organisational performance, transformational leadership predicts higher satisfaction with and trust in leadership, higher group performance (Keller, 1995) as well as employees' emotional commitment to organisations (Barling, Slater \& Kelloway, 2000). The transformational leader is also 'likely to be more pro-active than reactive, more innovative in ideas and less inhibited in ideational search for solutions' (Bass, 1985, p. 38). Because the transformational leadership model relies on collaboration in order to effect change, all of the four facets or leadership tasks are interpersonal in nature.

Radical change (like mergers in this study) has important implications for the practice of leadership. The results of several studies (in McCroskey, 2008) suggest that transformational leadership is one management practice that is likely to result in higher trends for both affective and normative organisational commitment during transformation. Therefore the transformational leadership model of Kouzes and Posner (1987) constituted the conceptual framework for the study, comprising five key transformational leadership behaviours. Kouzes and Posner (2001) suggest that successful transformational leaders demonstrate five distinct practices of leadership comprising the following 10 strategies, which outstanding leaders use to affect employees' and organisational performance: 
Practice 1 - Challenging the process: Search for opportunities by seeking innovative ways to change, grow and improve. Experiment and take risks by constantly generating small wins and learning from mistakes.

Practice 2 - Inspiring a shared vision: Envision the future by imagining exciting and ennobling possibilities. Enlist others by appealing to shared aspirations.

Practice 3 - Enabling others to act: Foster collaboration by promoting cooperative goals and building trust. Strengthen others by sharing power and discretion.

Practice 4 - Modelling the way: Find your voice by clarifying your personal values. Set an example by aligning actions with shared values.

Practice 5 - Encouraging the heart: Recognise individual contributions by showing appreciation for individual excellence. Celebrate accomplishments by creating a spirit of community.

This model has been used extensively to assess leadership behaviours across a variety of organisations, disciplines and demographic backgrounds (Kouzes \& Posner, 1987). In the current study we regarded effective leaders as those who demonstrated these five practices of transformational leaders. However, we want to emphasise that this conception of effective leadership is one of many possible approaches.

\section{Self-perception accuracy}

As this study focuses on the self-ratings of a group of managers in a higher education institution, the concepts managerial self-perception accuracy and self-perception accuracy have, for the purposes of this study, been treated as the same concept. Before self-perception accuracy can be defined it is necessary to distinguish it from related concepts appearing in the literature (e.g. self-awareness, selfactualisation, self-efficacy and self-esteem). Self-perception accuracy focuses on the image that individuals have of themselves and the accuracy of that image in comparison with how others perceive that individual and is a broader concept than self-actualisation, self-efficacy or self-esteem. Although all of these concepts deal with the perception that individuals have of themselves, self-awareness is broader in the sense that it focuses on whether or not that image is accurate in comparison with how others perceive that individual (McCarthy \& Garavan, 1999).

Many scholars see the concept of self-perception accuracy as closely linked to (and a major determinant of) the concept of self-awareness. For example, Atwater, Brett and Waldman (2003, p.95) state that 'comparisons of self- and other ratings provide an indicator of a manager's self-awareness and indicate blind spots'. Jokinen (2005, p. 205) describes self-awareness as 'having insight into your strengths and weaknesses, needs, drives, sources of frustration and typical reactions to problems', whilst Goleman (1998) suggests that an individual who is self-aware has a deep understanding of his or her emotions, strengths, weaknesses and drives.
Higgs (2002) describes self-awareness as having a realistic view of yourself and how others perceive you. Baumeister and Bushman (2008, p. 75) states that self-awareness entails 'attention directed at the self'. Atwater and Yammarino (1992, p. 143) define self-awareness as 'the individual's ability to assess other's evaluations of the self and to incorporate these assessments into one's self-evaluation'. This last definition was used in several other research studies (Bass \& Yammarino, 1991; Church, 1997; Godshalk \& Sosik, 2000; Krishnan, 2003; Sosik \& Megerian, 1999; Yammarino \& Atwater, 1997) involving multi-source feedback processes. The terms 'self-awareness' and 'self-perception accuracy' are used interchangeably in the literature on managerial career development (see e.g. McCarthy \& Garavan, 1999; Yammarino \& Atwater, 1993) and the authors follow this line of thinking in this article.

In this study, self-perception accuracy of the managers involved was defined operationally as the difference between the ratings of others and their own ratings with regard to their leadership effectiveness, that is, other-ratings minus self-ratings in terms of any of the five key transformational leadership behaviours as defined by Kouzes and Posner (2001). This approach therefore involved indicators of self/ rater congruence or agreement as determined by a direct comparison of the two (Van Velsor, Taylor \& Leslie, 1993). This does not mean that when self-perception accuracy is low, self-ratings are always 'false' and other ratings are always 'true', or vice versa. Self-ratings and other ratings should rather be seen as providing different perspectives on the same phenomena. The overlap or degree of consensus or agreement amongst the ratings is valuable information in itself. The appropriateness of using congruence in self-other ratings to measure the construct of self-perception accuracy is supported by Duval and Silvia (2001) who found that level of self-perception accuracy determines the degree of selfstandard comparison and influences congruity between self and standards in individuals.

Possible sources of influence (in Fletcher \& Baldry, 2000) upon an individual's self-assessment and the rating they receive from external feedback providers include:

- biographical characteristics

- individual characteristics

- cognitive processes.

The self-perceptions of individuals with high self-perception accuracy are both more reliable and valid because of their willingness to incorporate feedback into their selfperceptions. Conversely, low self-perception accuracy results in a tendency in individuals to ignore or discount negative feedback and might result in career derailment and negative attitudes towards work (Fletcher \& Baldry, 2000). Therefore, having insight into one's own defence mechanisms and the effect thereof is a prerequisite to be capable to rationally assess one's weaknesses as well as resources to deal with it effectively. 


\section{Measuring self-perception accuracy}

Although there is general agreement amongst researchers in this field about the broad definition of self-perception accuracy (namely that self-perception accuracy is the extent to which self-raters and other-raters agree on the level of competence the target individual attains), currently no consensus exists as how to best represent this self-other congruence conceptually or statistically (Fletcher \& Bailey, 2003). As a result studies in these areas have used a variety of self-other congruence measures. Common to most conceptualisations is the notion of having an index of self-other congruence, that is, the measure that will result in each individual having a 'score' ascribed to them (Fletcher \& Bailey, 2003). In this study the self-perception accuracy score is represented by the extent to which the ratings of the target manager and the others indicate that the behaviour statement is either characteristic or not characteristic for a particular target manager. Within the literature this has also been referred to a 'gap analysis', or 'Congruence- $d$ ' (Fletcher \& Bailey, 2003, p. 397). Congruence- $d$ is obtained by calculating the square root of the sum of squared (i.e. absolute) differences between self-rating and average other-rating score for each feedback questionnaire item and then dividing it by the pooled standard deviation of those scores (Church, 1997; Fletcher \& Bailey, 2003; Young \& Dulewicz, 2007). The smaller the ' $d$ ' scores, the higher the level of self-perception accuracy, with $d=0$ signifying complete agreement between self- and otherratings.

However, in the present study, it was decided not to use Congruence- $d$ indexes as described earlier with regard to representing university managers' (dis)agreement with the ratings of others. The reason for this was that Congruence- $d$ indexes do not contain information on the direction (overestimation versus underestimation) of any differences found. Therefore, for each of the five leadership practices mentioned in Kouzez and Posner's (1987) transformational leadership model, self-perception accuracy was instead always calculated as the result of the self-rating minus a composite (average) of several other-ratings on a particular leadership practice. The advantage of this approach is that it is sensitive not only to both to the actual level of competence perceived for a dimension but also to the degree of overestimation or underestimation, a distinction that earlier research has found to moderate predictor-outcomerelationships (Atwater \& Yammarino, 1992).

\section{Research questions and corresponding research hypotheses}

In agreement with what was described in a previous section as the overall purpose of the study, the overall research question investigated was: What is the relationship between managerial self-perceptions and the perceptions of others with regard to leadership effectiveness (LE) in a South African university context? This overall research question was answered by addressing the three research subquestions presented in Table 1, each in agreement with one of
TABLE 1: Research sub-questions and corresponding research hypotheses.

\begin{tabular}{|c|c|}
\hline Research sub questions & Corresponding research hypotheses \\
\hline $\begin{array}{l}\text { 1. What is the prevalence of } \\
\text { self-perception accuracy amongst } \\
\text { the managers regarding their } \\
\text { leadership effectiveness? }\end{array}$ & $\begin{array}{l}\text { 1. The prevalence of self-perception } \\
\text { accuracy amongst the managers will be low } \\
\text { with regard to all aspects/dimensions of } \\
\text { leadership effectiveness. }\end{array}$ \\
\hline $\begin{array}{l}\text { 2. What is the pattern of } \\
\text { significant correlations (if any) } \\
\text { between self-ratings and other- } \\
\text { ratings of managerial leadership } \\
\text { effectiveness? }\end{array}$ & $\begin{array}{l}\text { 2. When managers perceive a specific } \\
\text { aspect/dimension of their own leadership } \\
\text { effectiveness as being relatively low } \\
\text { or high, that dimension of leadership } \\
\text { effectiveness as perceived by others will } \\
\text { also be correspondingly relatively low or } \\
\text { high. }\end{array}$ \\
\hline $\begin{array}{l}\text { 3. What types of managerial self- } \\
\text { ratings (as classified according to } \\
\text { the aspect/ dimension of leadership } \\
\text { behaviour that is involved) play the } \\
\text { largest role with regard to other- } \\
\text { ratings of managerial leadership } \\
\text { effectiveness? }\end{array}$ & $\begin{array}{l}\text { 3. For each aspect/dimension of managerial } \\
\text { leadership behaviour studied, there is a } \\
\text { statistically significant regression model in } \\
\text { which leadership effectiveness (as measured } \\
\text { by other-ratings on that dimension of } \\
\text { leadership behaviour) is the dependent } \\
\text { variable and in which some/all of the } \\
\text { self-ratings of leadership behaviour are } \\
\text { independent variables. }\end{array}$ \\
\hline
\end{tabular}

the three specific research objectives mentioned previously. In addition, for each sub-question an empirically-based research hypothesis was formulated (see Table 1).

As can be seen in Table 1, the first research sub-question investigates the prevalence of self-perception accuracy amongst the managers, which is operationally defined to reflect congruence between a person's own and others' perceptions of leadership effectiveness. With regard to this sub-question it was hypothesised (based on the findings of authors mentioned in a previous section above, namely Alicke, Klotz, Breitenbecher, Yurak \& Vredenburg, 1995; Atkins \& Wood, 2002; Herbst et al., 2006), that the prevalence of self-perception accuracy amongst the managers will be low in terms of all aspects of leadership effectiveness (see hypothesis 1 in Table 1). It was hoped that the results pertaining to this aspect of the study would shed some light on the role that managerial self-perception could play in leadership effectiveness as rated by their peers, especially regarding over- or underestimation.

Both the second and third research sub-questions have to do with the relationship between managerial self-perceptions and the perceptions of others regarding leadership. This issue has yet to be examined in any higher education context (let alone in the context of a higher education institution in the throes of a merging process), because most past research on self-perception with regard to leadership (Young \& Dulewicz, 2007) has been conducted in the corporate world (Brackett, Lerner, Rivers, Salovey \& Shiffman, 2006; Fletcher \& Baldry, 2000; McCarthy \& Garavan, 1999; Sosik \& Megeriam, 1999). Such research needs to be replicated in higher education because to a large extent the manifestation of leadership is determined by the dynamic relationship that exists between the leader and the organisational context (Dulewicz \& Higgs, 2005).

However, on the basis of the research of the aforementioned authors in a corporate context, certain hypotheses could tentatively be formulated for the context of this study, 
namely that of a South African higher education institution in the process of merging and transition. For example, it was predicted (see hypothesis 2 in Table 1 ) that when managers in a higher education institution perceive their own leadership effectiveness as being relatively low, leadership effectiveness as perceived by other managers in the same institution would also be relatively low (and vice versa for relatively high ratings). In terms of the third research sub-question it was hypothesised that for each aspect of managerial leadership behaviour studied, there is a statistically significant regression model in which leadership effectiveness (as measured by other-ratings on that aspect of leadership behaviour) is the dependent variable and in which some/all of the self-ratings of leadership behaviour are independent variables (see hypothesis 3 in Table 1).

\section{Research design \\ Research approach}

A cross-sectional survey design whereby a sample of respondents is drawn from a population at a given point in time (Shaughnessy \& Zechmeister, 1991) was utilised to explore the aforementioned three research sub-questions and accompanying hypotheses. The general approach of the study was, in the terminology of Mouton \& Marais (1989), mainly descriptive (focusing on the classification of and interaction between variables) rather than explorative (investigating an entirely new phenomenon) or explanatory (focusing on cause and effect).

\section{Research method}

\section{Sampling}

In order to explore the relationship between managerial selfperceptions and perceptions of others regarding leadership effectiveness in a group of managers at a South African higher education institution, the whole population of staff in management positions $(N=204)$ at a recently merged higher education institution was approached to participate in the project on a voluntary basis. Permission to conduct the research, to publish the research results and to incorporate the case studies in this article, was obtained from the institution and all its managers agreed to participate. The realised sample consisted of 137 managers, that is, the response rate was $67 \%$.

For each of these 137 managers, six staff members (who were known to have work contact with that manager) were approached to provide their ratings of the managers' leadership behaviour. A total of 822 LPI Observer forms were sent out of which 603 (73\% response rate) forms were completed and returned (a mean number of 4.4 observers per participant). The observer comprised the participants' manager, subordinates (3 per manager) and peers ( 2 per manager). The target manager also completed a self-assessment version of the LPI. It would have been an advantage to be able to examine the feedback from subordinates and peers separately; however, in order to guarantee the anonymity of the raters all observer data were integrated into one 'other-rating' score for each manager.

\section{Research participants}

As can be seen in Table 2, the total of 137 managers who agreed to participate in the study consisted of 93 men and 44 women, whilst 94 managers were White and 43 were Black. Of these participants $12.4 \%$ (17 participants) held a senior management position (deans, chief directors), $81 \%$ (111 participants) were middle-level managers (heads of departments) and $6.6 \%$ (9 participants) were supervisors (divisional heads). The average age of the respondents was 46.1 years and $75 \%$ had a post-graduate qualification. Anonymity in respect of their individual scores was guaranteed to all participants.

\section{Measuring instrument}

The Leadership Practices Inventory (LPI) (which is described more fully at a later stage), was administered to the sample of 137 managers.

The measure of self-perception accuracy as well as the measure for leadership effectiveness for each target manager was derived from data collected on the Leadership Practices Inventory (LPI). Both the self-rating and the other-rating forms of the LPI (Kouzes \& Posner, 1988) are 30-item leadership inventories with each item corresponding to one of 5 leadership practices or competency dimensions. Briefly, the dimensions were:

1. challenging the process

2. inspiring a shared vision

3. enabling others to act

4. modelling the way

5. encouraging the heart.

Each practice was measured by six behavioural descriptions, rated on a 10-point Likert scale anchored by 'Almost never' (1) up to 'Almost always' (10), therefore yielding a total score for each respondent that could range from 6 to 60 on each

TABLE 2: Biographical details of the respondents.

\begin{tabular}{|c|c|c|c|c|c|c|}
\hline \multirow[t]{2}{*}{ Gender } & \multirow[t]{2}{*}{ Race } & \multicolumn{3}{|c|}{ Management level } & \multirow[t]{2}{*}{ Total } & \multirow[t]{2}{*}{$\%$} \\
\hline & & $\begin{array}{c}\text { Senior } \\
\text { (Deans, Chief Directors) }\end{array}$ & $\begin{array}{c}\text { Middle } \\
\text { (Heads of Departments) }\end{array}$ & $\begin{array}{c}\text { Supervisor } \\
\text { (Divisional Heads) }\end{array}$ & & \\
\hline \multirow[t]{2}{*}{ Female } & White & 2 & 28 & 3 & 33 & 24.10 \\
\hline & Black & 2 & 7 & 2 & 11 & 8.00 \\
\hline \multirow[t]{2}{*}{ Male } & White & 5 & 50 & 3 & 61 & 44.50 \\
\hline & Black & 6 & 26 & 1 & 32 & 23.40 \\
\hline Total & & $17(12.4 \%)$ & $111(81.0 \%)$ & $9(6.6 \%)$ & 137 & 100.00 \\
\hline
\end{tabular}


practice. Validation studies conducted consistently over a 10year period have confirmed the reliability and validity (both face validity and predictive validity) of the LPI. Internal reliabilities for the LPI Observer range from 0.81 to 0.92 for the five practices whilst test-retest reliability was at 0.93 or higher (Kouzes \& Posner, 1995).

To measure leadership effectiveness in this study, the LPI was used to obtain not only the self-ratings of the sample of managers, but for each manager a number of observer scores (other-ratings) were also obtained regarding each practice. In each case the composite other-score (i.e. the average of the other-ratings) was then taken as an indication of the others' perceived leadership effectiveness (LE) of that manager. To measure self-perception accuracy for each of the five leadership practices mentioned in Kouzer and Posner's (1987) transformational leadership model, self-perception accuracy was calculated as the result of the self-rating minus a composite (average) of several other-ratings on a particular leadership practice. As stated previously, the advantage of this approach is that it is sensitive not only to both to the actual level of competence perceived for a dimension but also to the degree of overestimation or underestimation.

\section{Research procedure}

Participation was voluntary and the first author provided hard copies of the LPI to the participants in the institution. The LPI questionnaires of the target managers were administered in groups and collected directly after they had been completed. The informed consent letter explained to the participants that the information in the completed questionnaires would be treated confidentially. The nominated raters (observers) completed the LPI for the target manager anonymously and sent it back to the researcher via the internal mail system.

\section{Statistical analysis}

This study was designed to explore the relationship between managerial self-perceptions (as measured by means of selfratings on the five leadership competency dimensions of the LPI) and transformational leadership effectiveness, as measured by means of composite other-ratings (the average of about four other-ratings obtained for each manager) on the same leadership dimensions. In order to address the first research hypothesis stating that the prevalence of selfperception accuracy amongst the managers will be low regarding all aspects of leadership effectiveness, the following was done: on each of the five leadership dimensions the mean self-rating scores and the mean composite other-ratings were calculated and compared by means of Student's $t$-test for any statistical differences (i.e. when $p \leq 0.05$ ). Similarly, for every manager a number of self-perception accuracy scores were calculated (each as a composite other rating minus a corresponding self-rating). On all dimensions the means of all the managers' accuracy scores were then tested for statistically significant $(p \leq 0.05)$ differences from zero, again by means of Student's $t$-test.

Next, the study also set out to investigate (in accordance with the second research hypothesis) whether or not the managerial self-ratings on the five leadership dimensions of the LPI, would correlate with transformational leadership effectiveness (the corresponding composite other-ratings). Accordingly, Pearson correlation coefficients between self-ratings and composite other-ratings were calculated separately for each of the five different leadership dimensions, as well as for total scores. Finally, in order to address the third research hypothesis, a number of stepwise regression analyses were utilised to investigate which aspects of leadership self-perception (independent variables) could best predict transformational leadership behaviour as rated by others (dependent variable) - as a whole and also regarding each of the five leadership dimensions. Each analysis endeavoured to determine the best statistically significant model and the following stepwise criteria were used for including/excluding any of the five potential independent variables (namely the self-ratings with regard to 'challenging', 'inspiring', 'enabling', 'modelling' and 'encouraging'):

Probability-of- $F$-to-enter $<=0.05$

Probability-of- $F$-to-remove $>=0.10$.

The main statistical package used for the various analyses of the data was SPSS version 17.

\section{Results}

In this study the LPI was used to obtain not only the selfratings of the sample of managers, but for each manager a number of observer scores (other-ratings) were also obtained in terms of each leadership dimension. In order to test the reliability of these scales, Cronbach Alpha scores were calculated. High Alpha scores were obtained for both the self-

TABLE 3: Indexes of leadership effectiveness and self-perception accuracy ( $N=137)$.

\begin{tabular}{|c|c|c|c|}
\hline \multirow[t]{2}{*}{ Leadership dimensions } & \multicolumn{2}{|c|}{ Leadership effectiveness (LE) } & \multirow{2}{*}{$\begin{array}{c}\text { Self-perception accuracy } \\
\text { Difference scores } \\
\text { (Composite Other-ratings minus } \\
\text { Self-ratings: means) }\end{array}$} \\
\hline & $\begin{array}{c}\text { Perceived effectiveness scores by others } \\
\text { (Composite/average } \\
\text { Other-ratings: means }{ }^{* * *} \text { ) }\end{array}$ & $\begin{array}{l}\text { Self perception scores } \\
\text { (Self-ratings: means***) }\end{array}$ & \\
\hline Inspiring a shared vision & 43.11 & $46.65 *$ & $-3.53^{* *}$ \\
\hline Enabling others to act & 46.81 & $51.52 *$ & $-4.71 * *$ \\
\hline Modelling the way & 45.95 & $50.29 *$ & $-4.34 * *$ \\
\hline
\end{tabular}

*, Self-ratings significantly different from Other-ratings on same dimension $(p<0.05) ;{ }^{* *}$, Difference scores on each dimension significantly different from zero $(p<0.05) ;{ }^{* * *}$, Mean Other-ratings and Self-ratings scores on each dimension all significantly different $(p<0.05)$ from those on other dimensions (exception: Other-rating (Challenging) vs. Other-rating (Inspiring). 
ratings (0.89) and the other-ratings (0.95) and from this it can be concluded that the reliability of the ratings obtained by means of the LPI can be considered as being good - usually an Alpha score of 0.7 is considered to be satisfactory (Garson, 2010).

The next data processing step was to calculate and compare the various numerical indicators of leadership effectiveness that were needed to address the first research hypothesis, namely that the prevalence of self-perception accuracy amongst the managers will be low with regard to all aspects of leadership effectiveness.

Table 3 shows that on all five leadership competency dimensions the participating managers' self-ratings were consistently lower than the average other-ratings by the observers. All the mean self-ratings of leadership effectiveness were statistically significantly different (using paired $t$-tests) from the corresponding means of the otherratings (in each case the null hypothesis that there would be no differences between the means was rejected because of the obtained probability $p<0.001$, which more than satisfied the criterion of $p \leq 0.05$ ). The alternative hypothesis that the target managers and their peers differed markedly from each other with regard to their respective perceptions of the managers' leadership effectiveness was therefore accepted. It was also found that all the mean self-perception accuracy scores were negative (rejecting the null hypothesis that the self-perception accuracy scores would not be different from zero on the grounds that it had a probability $p<0.001$ which satisfied the criterion of $p \leq 0.05$ and therefore the alternative hypothesis was accepted that the accuracy scores were significantly below zero). From this finding it is reasonable to conclude that the target managers tended to overestimate their own leadership effectiveness regarding all five practices. An alternative conclusion is theoretically also possible, namely that the managers' self-ratings were correct and that the other-ratings rather tended to underestimate the managers, but this explanation was rejected on the grounds that each other-rating was a composite score based on the perceptions of at least four other persons and therefore logically possibly more credible than the single corresponding self-rating.

Other interesting information that can be gleaned from Table 3 is that the mean other-ratings and mean self-ratings scores on each dimension were mostly significantly different $(p<0.05)$ from those on other dimensions. From this it can be concluded that the managers tended to be rated highest (by themselves and by others) on 'Enabling others to act', but whilst the managers rated themselves lowest on 'Challenging the process', the others rated them lowest on 'Inspiring a shared vision'. The means in the table were also studied further in terms of the age and gender of the target managers, but no other clear patterns emerged.

Although this data show that the managers exhibited low self-perception accuracy (in other words, the other-ratings were consistently lower than the self-ratings), this does not rule out the possibility of other types of interactions (such as correlations) between the two sets of scores, as referred to in the second research hypothesis (namely that when managers perceive a specific aspect/dimension of their own leadership effectiveness to be relatively low or high, that aspect of leadership effectiveness as perceived by others would also be correspondingly relatively low or high).

The next data processing step was therefore to study the relationship between self-perceptions and other-perceptions of leadership effectiveness further by calculating Pearson correlation coefficients between the managers' self-ratings and the composite other-ratings. This was done separately on each of the five different leadership dimensions, where all five self-rating totals were in turn correlated with each of the five other-rating totals. These 25 correlations are presented in Table 4 . The five correlations in the shaded diagonal cells of the table are those that have the most bearing on the second research hypothesis of this study, whilst the other correlations provide additional contextual information about the broader pattern of significant correlations between self-ratings and other-ratings of managerial leadership effectiveness.

In Table 4 it can firstly be seen that statistically significant correlations (criterion: $p \leq 0.05$ ) were found between otherrating and self-rating scores on three of the five different leadership dimensions. These three dimensions were the following:

- 'Challenging the process': Self-ratings on this dimension correlated positively and significantly $(p<0.05)$ with the other-ratings on this same dimension ('Challenging the process').

TABLE 4: Pearson correlations between other-perceptions and self-perceptions of leadership effectiveness.

\begin{tabular}{|c|c|c|c|c|c|c|}
\hline \multirow[t]{2}{*}{ Other-perceptions } & \multirow[t]{2}{*}{ Other-rating } & \multicolumn{5}{|c|}{ Self-perceptions - Variables involved Self-rating } \\
\hline & & Challenging & Inspiring & Enabling & Modelling & Encouraging \\
\hline \multirow[t]{2}{*}{ Challenging the process } & Challenging & $0.190^{*}$ & 0.163 & -0.084 & -0.091 & 0.056 \\
\hline & & $p=0.026$ & $p=0.057$ & $p=0.329$ & $p=0.292$ & $p=0.515$ \\
\hline \multirow[t]{2}{*}{ Inspiring a shared vision } & Inspiring & $0.183^{*}$ & $0.223 * *$ & -0.012 & -0.02 & 0.115 \\
\hline & & $p=0.032$ & $p=0.009$ & $p=0.887$ & $p=0.817$ & $p=0.181$ \\
\hline \multirow[t]{2}{*}{ Enabling others to act } & Enabling & 0.031 & 0.147 & 0.055 & 0.028 & 0.085 \\
\hline & & $p=0.717$ & $p=0.087$ & $p=0.527$ & $p=0.745$ & $p=0.322$ \\
\hline \multirow[t]{2}{*}{ Modelling the way } & Modelling & 0.045 & 0.143 & 0.026 & 0.126 & 0.109 \\
\hline & & $p=0.599$ & $p=0.095$ & $p=0.762$ & $p=0.142$ & $p=0.206$ \\
\hline \multirow[t]{2}{*}{ Encouraging the heart } & Encouraging & 0.071 & $0.169^{*}$ & 0.021 & 0.091 & $0.194 *$ \\
\hline & & $p=0.407$ & $p=0.048$ & $p=0.810$ & $p=0.288$ & $p=0.023$ \\
\hline
\end{tabular}

*, Correlation is statistically significant; 2-tailed; $p<0.05$ 
- 'Inspiring a shared vision': The other-rating on this dimension correlated significantly $(p<0.01$, which was better than the requirement of $p \leq 0.05$ ) with the selfratings on this dimension ('Inspiring a shared vision') and also significantly $(p<0.05)$ with the self-ratings on the dimension 'Challenging the process'.

- 'Encouraging the heart': The other-rating on this dimension correlated significantly $(p<0.05)$ not only with self-ratings on this dimension ('Encouraging the heart'), but also with the self-ratings on the dimension 'Inspiring a shared vision'.

From these significant correlations it can be deduced that there are grounds for accepting the second research hypothesis on the aforementioned three leadership dimensions. In other words, on three of the five leadership dimensions studied there was evidence that a relatively high other-rating tended to be associated with relatively high self-rating scores for that dimension (and vice versa). However, this research hypothesis was rejected on the two remaining leadership dimensions, namely 'Enabling others to act' and 'Modelling the way'. It is further interesting to note that of all the self-perception variables, it was only the self-rating with regard to 'Inspiring a shared vision' that correlated with more than one of the other-rating variables (including with the 'total of all other ratings combined'). It should however be noted that all the previously mentioned statistically significant correlations were relatively small and that in practice their effects can be expected to also be relatively small.

The final step in the data processing process was to conduct a number of stepwise regression analyses to investigate the question of what types of managerial self-ratings (as classified according to the various dimensions of leadership behaviour that were studied) play the largest role regarding other-ratings of managerial leadership effectiveness. As formulated in the third research hypothesis, it was predicted that for each dimension of managerial leadership behaviour there would be a statistically significant regression model in which leadership effectiveness (as measured by other-ratings on that dimension of leadership behaviour) would be the dependent variable and in which some/all of the self-ratings of leadership behaviour would be the independent variables.

A total of six stepwise regression analyses were conducted, one analysis involving the leadership effectiveness otherratings in each of the five leadership dimensions and another analysis involving a total/combined score of the leadership effectiveness other-ratings over all the dimensions. These other-ratings on the leadership dimensions were taken one-ata-time as the dependent variable for each calculation, whilst all the self-rating scores on these dimensions were included as the independent variables in all the computations. In all calculations the usual stepwise regression criteria applied in terms of accepting new variables into the model only on a probability of $p<0.05$ and of excluding a variable from the model on the basis of a probability of $p<0.10$ ).

According to Chen, Ender, Mitchell and Wells (2003) a possible problem in regression analyses that has to be taken into account, is that of collinearity (often also interchangeably referred to as multicollinearity), which can arise when predictor variables are highly collinear (linearly related), which in turn can lead to inaccurate estimations of regression coefficients. The authors also point out that in the statistical package SPPS (used in this study) the 'statistics tolerance' and 'VIF' (Variance Inflation Factor) can be calculated as a check for collinearity and that collinearity is only a problem if the value of 'tolerance' is less than 0.10 or that the value of 'VIF' is greater than 10. The values in Table 5 therefore show that for this study collinearity was not a problem.

The results in Table 5 show on which leadership dimensions statistically significant $(p<0.05)$ regression models could be found and also which of the independent variables (also called predictor variables) fitted best in each of these models; in other words, which of the self-rating variables best predicted each of (i.e. played the largest role in) the leadership other-ratings variables studied. It was found that statistically significant regression models could be found on three leadership dimensions ('Challenging the process', 'Inspiring a shared vision' and 'Encouraging the heart') and regarding the combined other other-ratings over all five leadership dimensions. This meant that the third research hypothesis could be accepted on these three leadership dimensions (and also with regard to total scores over all five leadership dimensions). This research hypothesis was however rejected on the two remaining leadership dimensions, namely 'Enabling others to act' and 'Modelling the way'. It is interesting to note that this pattern of acceptance/rejection is similar to what was found earlier regarding the second research hypothesis (dealing with correlations on the various dimensions).

In addition, the following detailed findings were made. It was found that:

- The leadership effectiveness (other-ratings) regarding the leadership dimension 'Challenging the process' was best predicted by (i.e. was most dependent on) two variables, namely the self-ratings on 'Challenging the process' and the self-ratings on 'Enabling others to act'.

- The other-ratings on the dimension 'Inspiring a shared vision' were also best predicted by two variables, namely the self-ratings on 'Inspiring a shared vision' and the selfratings on 'Enabling others to act'.

- Leadership effectiveness (other-ratings) regarding the leadership dimension 'Encouraging the heart' was most dependent on the self-rating on that same dimension ('Encouraging the heart') and on 'Enabling others to act'.

- Leadership effectiveness as a whole (the total of the other-ratings over all five dimensions) was best predicted by the self-rating on one dimension, namely 'Inspiring a shared vision'.

\section{Discussion}

The purpose of this study was to explore the relationship between managerial self-perceptions and perceptions of others regarding leadership effectiveness in a group 
TABLE 5: Stepwise regression analyses: Other-perceptions (dependent variable) and self-perceptions (independent variables).

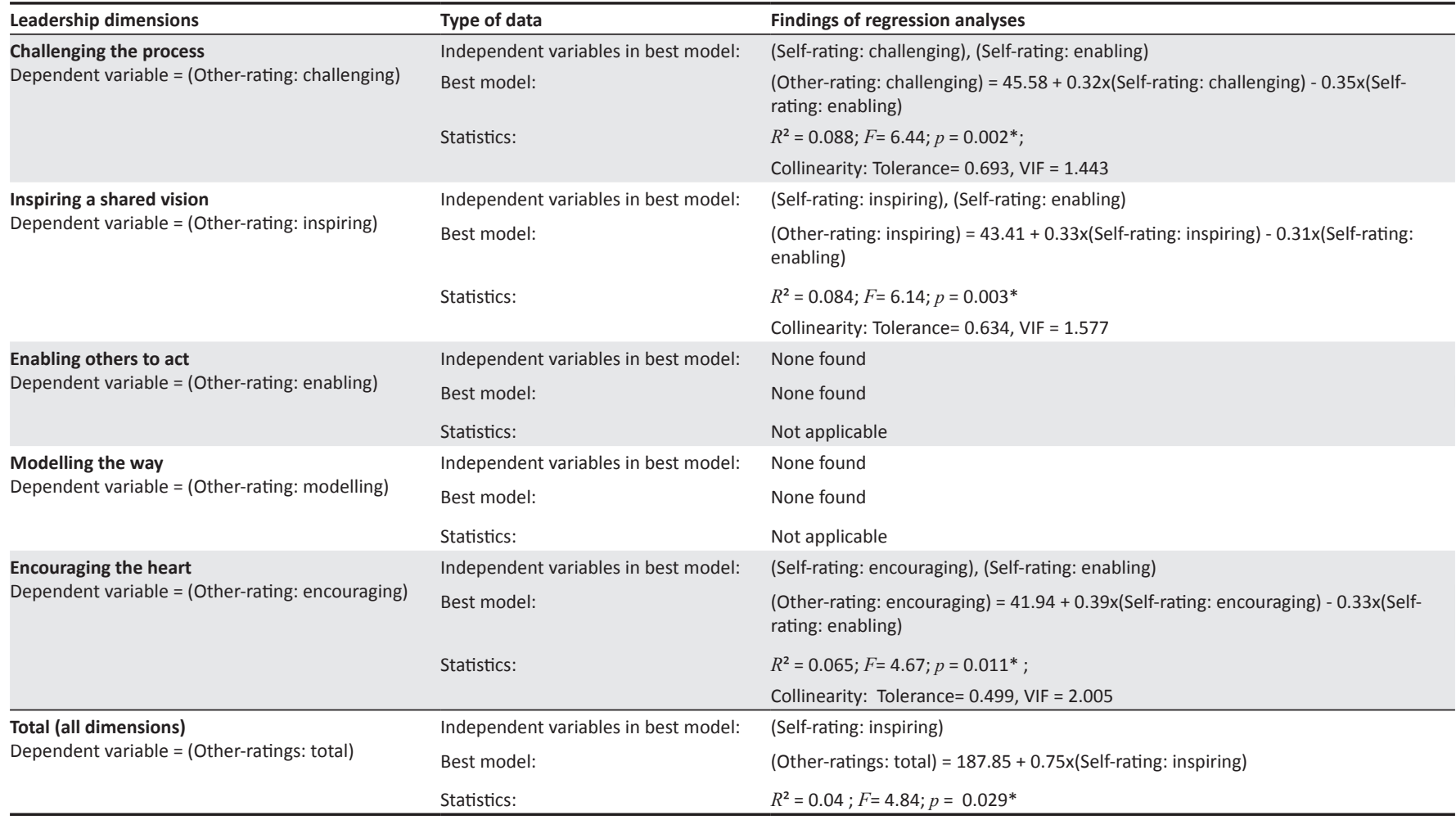

*, Statistically significant $F$ value $(p<0.05)$.

of managers in the context of a South African university undergoing a merging process. More specifically, the research set out to study the prevalence of self-perception accuracy amongst the managers and to explore the patterns of interaction between self-perception accuracy regarding their leadership behaviour and perceived transformational leadership behaviour (as measured by composite 'other'ratings). In terms of the first issue of prevalence of selfperception accuracy amongst the managers, it was hypothesised that the prevalence of self-perception accuracy amongst the managers would be low with regard to all aspects of leadership effectiveness. The findings confirmed that this was the case in all the dimensions of leadership that were studied. Additional findings were that the highest leadership ratings (both by the mangers and by the others) were found on the dimension 'Enabling others to act', but whilst the mangers rated themselves lowest on 'Challenging the process', the others rated them lowest on 'Inspiring a shared vision'.

The findings in relation to managers overestimating their own leadership abilities (and therefore exhibiting low selfperception accuracy) are in agreement with this expectation and also confirm the view by researchers (referred to in Detweiler-Bedell, Deitweiler-Bedell \& Salovey, 2006) that individuals tend to be overly optimistic about their own prospects compared to the prospects of others and they generally believe that their abilities and traits are above average. One source of bias in self-assessments is cognitive factors, in particular limited and inherently egocentric information processing (see Chambers \& Windschitl,
2004). This is in line with Sosik (2001) who states that overestimaters may be viewed by their subordinates as unreceptive, inauthentic, self-centred and uncaring. These adverse perceptions are unlikely to build follower trust and commitment and are confirmed by several studies (referred to in Sosik, 2001) which have linked self-perception accuracy with trust. The results of the study by Sosik (2001) provide evidence that subordinates of overestimaters demonstrated the lowest level of trust and organisational commitment. Given the fact that the target managers in this study were a high level group in intellectual terms (they were all graduates and many had postgraduate qualifications), it came as a surprise that the self-perception accuracy results obtained here contradict some previous studies (Fletcher \& Baldry, 2000) which indicated that high self-perception accuracy is most strongly associated with intellectual and social detachment, analytical inclination and ability. It also contradicts findings in the person-perception field, where it has been suggested that cognitive factors may be of primary importance in forming accurate judgements of others (Flecther \& Baldry, 2000).

Another source of bias in self-assessments is that people have a vested interest in protecting and boosting their selfesteem. As stated before, the study was conducted within a post-merger context. One possible scenario which would be in line with the low level of self-perception accuracy that was found could be that the overestimation might be a type of defence mechanism masking internal anxieties due to the socio-emotional complexities managers had to deal with. Radical changes like mergers challenges staff members' most 
basic assumptions and socially constructed reality about the nature of their organisations. Challenging this source of cognitive and emotional stability is comparable to attacking a core identity and, thus, could trigger strong defence mechanisms, such as anxiety and defensiveness (Huy, 1999). Similarly, Strauss (2005, p. 466) notes that individuals may feel compelled to rate themselves higher than they truly feel due to 'an unconscious protection mechanism or conscious effort to manage the impressions of others'. This notion is supported by Mayer and Geher (1996) who observed a significant negative relationship between emotional intelligence and defensiveness. The reason for this, according to Boyatzis (2007), is that:

our mind protects us from potentially threatening input to our conscious realizations about ourselves through the conscious use of ego-defence mechanisms. These mechanisms also conspire to delude us into an image of who we are that feeds on itself, becomes self-perpetuating and eventually may become dysfunctional.

(Boyatzis 2007, p. 162)

This phenomenon is supported by the findings of a study by Maree and Eiselen (2004) who found that the current change and transformation in higher education hampers the development of the emotional intelligence of academics. Becker et al. (2004) concur by providing evidence of the negative impact of a merger on the self-image and self-worth of staff members. Thus, it seems as if the managers in this study did appear to have a defensive mechanism operating in which they felt compelled to report unduly high self-ratings.

The second research hypothesis predicted that a pattern of possibly significant correlations between self-ratings and other-ratings of managerial leadership effectiveness would emerge when managers perceive their own leadership effectiveness as being relatively low on a particular dimension, leadership effectiveness as perceived by others would also be relatively low (and vice versa for relatively high ratings) on that dimension. This prediction was confirmed by the findings on three of the five leadership dimensions ('Challenging the process', 'Inspiring a shared vision' and 'Encouraging the heart'). It can therefore be concluded that a pattern of significant correlations did exist between self-ratings and other-ratings of managerial leadership effectiveness regarding these three dimensions. This supports the conceptualisation of 'relative self-awareness' which reflects the extent to which the target manager and their raters agree on the target's least and most effective behaviours, rather than competence per se (Fletcher \& Bailey, 2003). However, this can reflect simply the extent to which self- and other-ratings covary, rather than actual self-awareness which is also the main criticism of this conceptualisation.

In terms of the third hypothesis dealing with the existence of regression models that would indicate what types of managerial self-ratings of leadership behaviour would best predict other-ratings of managerial leadership effectiveness, it was found that the other-ratings on three of the five dimensions of leadership behaviour (namely 'Challenging the process', 'Inspiring a shared vision' and 'Encouraging the heart') were significantly dependent on certain types of self-ratings by managers (especially those self ratings in the same leadership dimension as the otherratings). The third research hypothesis could therefore be accepted regarding these three leadership dimensions. Once again, in the post-merger context of this study it is understandable why these three dimensions emerged as the best predictors of leadership effectiveness. The need for a new institutional vision, the clashes in corporate culture as well as the personal and emotional impact associated with mergers could be a possible explanation for this finding. It is also interesting that in this study all the interactions and dependencies between the two sets of scores (the self- and other-ratings) were found in spite of the previously mentioned evidence of consistently low self-perception accuracy (in other words, other-ratings that were consistently lower than self-ratings).

\section{Conclusion}

It can be concluded from this research that more effective leaders have a greater level of self-perception accuracy and, at the very least, are better at assessing and/or rating their own behaviours in the workplace. The results of this study therefore are in line with other work regarding the significance of self-awareness for leadership effectiveness (Fleenor, McCauley \& Brutus, 1996; Fletcher, 1997; Higgs \& Aitken, 2003; Krishnan, 2003; Tekleab, Sims, Yun, Tesluk \& Cox, 2008; Van Velsor, Taylor \& Leslie, 2009). Also relevant are the findings of Krishnan (2003), who provides evidence that leaders who underestimate their leadership effectiveness are seen more favourably by others as compared leaders who overestimate themselves. This suggests that leaders should become less complacent and more self-critical about their effectiveness. According to Zaccaro, Kemp and Bader (2004) personal attributes play a more substantial role in predicting leadership effectiveness as leadership situations become more complex and varied. Therefore, assessment data (e.g. personality, ability, task related characteristics and multi-rater feedback) either from oneself or by means of reflection from others, should be incorporated into leadership development experiences.

\section{Suggestions for future research}

The present study was constrained in terms of the selfperception accuracy measures used and it would certainly be of interest to explore the relationship between leadership effectiveness and self-perceptions with a wider range of self-perception accuracy measures. Although the ratings used to group managers into agreement groups were independent of the ratings used to measure leadership effectiveness, both sets of ratings came from the same instrument (LPI). Thus the measure of self-perception accuracy and the measure of leadership effectiveness were based on the same items. This research should therefore be replicated with measures of self-perception accuracy separate from measures of leadership effectiveness (e.g. 
performance appraisal ratings, work group achievement and team morale). A greater knowledge of the attributes associated with self-awareness and effective assimilation of feedback may thus facilitate an indirect assessment of the individual's likely level of this attribute (Fletcher \& Baldry, 2000). Future research is needed to replicate the findings that emerged in this study that in spite of wide-spread low self-perception accuracy amongst managers regarding all five leadership practices or competency dimensions, self-perception moderates transformational leadership behaviours. Finally, there is a definite need to develop valid measures of self-awareness that are independent of multirater assessment instruments. Therefore, future research could also be directed at determining alternative and more direct methods for assessing self-perception accuracy beyond the ratings congruence paradigm. Finally, considerably more work needs to be done to determine the emotional effects of large scale change interventions like mergers on the selfperception accuracy of managers.

\section{Limitations of the study}

Self-perception accuracy or self-awareness is a difficult area to research. The present study sought to overcome a number of methodological problems that have been present in previous research. However, possible limitations could be that self-other agreement was looked at only regarding leadership effectiveness as measured by the LPI. Furthermore, the range/scope of the study and subsequently the possibility for generalisation is limited because only one institution was involved. Because of the high costs involved in the administration and scoring of the measure used in this study, it was decided to limit the current research to one institution only. It is also a limitation of this study that the statistically significant correlations on which some of the conclusions were based were relatively small and that the practical impact of these correlations can be expected to also be relatively small. Finally, although the whole population of management staff was approached to participate in the study, some did not participate. The reasons why some staff members decided not to participate remain unknown. In terms of their self-awareness and leadership effectiveness, non-participants may very well differ from those who participated.

\section{Recommendations}

In the introduction it was pointed out that self-perception accuracy is usually seen as an important attribute for leadership effectiveness. The results of this study provided conclusive evidence of a low level of self-perception accuracy amongst the managers, but that in spite of this, selfperception still moderated their transformational leadership behaviours as perceived by peers. These results suggest that the underlying mechanisms involved in accurate self-assessments must be explored fully. Clearly some important and potentially useful factors are at work. It is a challenge for researchers to better understand these in the applied setting, as perhaps more than other measures, self- perception accuracy may be affected by the context (in this study a recently merged institution) the participants find themselves in.

As stated by Brutes, Fleenor and Tisak (1999, p. 319), 'discrepancies between self-evaluations and others' evaluations allow for rare insight into one's interpersonal world'. The relative low self-perception accuracy (overestimation) amongst participants raises questions regarding the impact of socio-emotional complexities associated with a merger on managers' emotional wellbeing and personal growth and development. According to Boyatzis (2007, p. 164) our relationships are an essential part of our environment. These relationships and groups that a manager forms part of give them a sense of identity, guide them as to what is appropriate and 'good' behaviour and provide feedback on behaviour. In sociology they are referred to as 'reference groups'. From the findings of this research it is evident that in this new merged environment of complex change, managers cannot sustain these uncertainties without support.

To respond effectively to the transformation challenges managers in higher education and elsewhere are faced with, they will have to acquire new skills and leadership practices. This will require the ability for continuous personal transformation and life-long learning; Antonacopoulou defines learning as the 'liberation of knowledge through learning and self-questioning' (2006, p. 460). Therefore, for learning to take place self-awareness is required as you can only change that which you are aware of. Unfortunately, the importance of self-perception accuracy in leadership development is often overlooked and hence leadership development is often perceived as an external process (Souba, 2006). According to London (2002) feedback is central to leadership development. Therefore, managerial development practices should sensitise managers to what is essentially introspective or retrospective and provide opportunities for them to reflect upon and question their leadership practices. Viewed in the context of this study an important leadership development challenge for higher education is to embark on feedback intensive leadership development processes that provide participants with comprehensive feedback in a supportive environment. Individuals should be trained to give, receive and seek out constructive feedback. Through intentional change theory ${ }^{1}$ (where the ideal self is the emotional driver of intentional or desired change) managers might benefit from coaching to assist them in exploring their 'blind spots' and increasing their accuracy regarding the way they are perceived by others. As argued by Nisbett and Toss (1980):

1.Intentional change theory (ICT) presents a framework to view and interpret how or ganisations and individuals achieve desired, sustainable change. It outlines both or ganisations and individuals achieve desired, sustainable change. It outlines both the process and the phases of the change process that are central for sustainable change to occur. In considering ICT at the individual level, the phases represent various stages that a person cycles through in his or her journey toward desirable, sus tainable change in one's behaviour, thoughts, feelings and perceptions. It is 'desired' in that the person wants it to occur and 'sustainable' in that it lasts (Boyatzis, 2006). 
In general, misperceptions make us less able to remedy the situations that threaten us or give us pain than do accurate perceptions. In a sense, they poorly serve the goals of maximizing pleasure and minimizing pain in the long term.

(Nisbett \& Toss, 1980, p. 234)

In a time of continual change in higher education and elsewhere, the need for increased levels of self-awareness and interpersonal skills is critical challenge for staff development practitioners. As further research provides greater support for the importance of self-perception accuracy, the process of helping leaders become more effective could focus on giving more attention to assist managers to become more self-critical regarding their own leadership practices. The development, implementation and maintenance of a high-quality multisource feedback system could enhance institutional effectiveness in dynamic and complex contexts where selfpresentation and continuous personal improvement are becoming increasingly important.

\section{References}

Alicke, M.D., Klotz, M.L., Breitenbecher, D.L., Yurak, T.J., \& Vredenburg, D.S. (1995). Personal contact, individuation, and the better-than-average-effect. Journal of Personality and Social Psychology, 68, 804-825.

Antonacopoulou, E.P. (2006). The relationship between individual and organizationa learning: New evidence from managerial learning practices. Management Learning, 37(4), 455-473.

Astin, W.A., \& Astin, H. S. (2000). Leadership Reconsidered: Engaging higher education in social change. Retrieved September 19, 2008, from http://www.wkkf.org/Pubs/ CCT/Leadership/Pub3368.pdf

Atkins, P.W.B., \& Wood, R.E. (2002). Self-versus others' ratings as predictors of assessment center ratings: Validation evidence for 360-degree feedback programs, Personnel Psychology, 55(4), 871-904.

Atwater, L.E., \& Yammarino, F.J. (1992). Does self-other agreement on leadership perceptions moderate the validity of leadership and performance predictions? Personnel Psychology, 45, 141-164.

Atwater, L.E., Brett, J.F., \& Waldman, D. (2003). Understanding the benefits and risks of multisource feedback within the leadership development process. In S.E. Murphy \& R.E. Riggio (Eds.), The future of leadership development, (pp. 89-106) New Jersey: Lawrence Erlbaum Associates Inc.

Barling, J.F., Slater, F.J., \&. Kelloway, E.K. (2000). Transformational leadership and emotional intelligence: an exploratory study. Leadership and Organization Development Journal, 21(2), 157-161.

Bass, B.M. (1985). Leadership and performance beyond expectations. New York: Free Press.

Bass, B.M. (1998). Transformational leadership: Industry, military and educational impact. Mahwah, NJ: Erlbaum.

Bass, B.M., \& Avolio, B.J. (1993). Transformational leadership: A response to critiques. In M.M. Chermers \& R. Anyman (Eds.), Leadership theory and research Perspectives and directions, New York: Free Press.

Bass, B.M., \& Yammarino, F.I. (1991). Congruence of self and others' leadership rating of naval officers for understanding successful performance. Applied Psychology: An International Review, 40(4), 437-354.

Bateman, T.S., \& Snell, S.A. (2002). Management: Competing in the new era: 5 th edn New York: Irwin McGraw Hill.

Baumeister, R.F., \& Bushman, B.J. (2008). Social Psychology and Human Nature. Belmont, USA: Thomson Wadsworth

Becker, L.R., Beukes, L.D., Botha, A., Botha, A.C., Botha, J.J., Botha, M., et al. (2004) The impact of university incorporation on college lecturers. Higher Education, 48, 153-172.

Bosch, A. (2006). The effect of a merger in higher education on staff members: the importance of change management. Unpublished master's thesis, University of Johannesburg, Johannesburg.

Boyatzis, R.E. (2006). The ideal self as the driver of intentional change. Journal of Management Development, 25(7), 624-642.

Boyatzis, R.E. (2007). Developing emotional intelligence through coaching for leadership, professional and occupational excellence. In R. Bar-On, J.G. Maree \& M.J. Elias (Eds.), Educating people to be emotionally intelligent (pp. 155-168). Johannesburg: Heinemann Publishers (PTY).

Brackett, M.A., Lerner, S.E., Rivers, S.E., Salovey, P., \& Shiffman, S. (2006). Relating emotional abilities to social functioning: A comparison of self-report and performance measures of emotional intelligence. Journal of Personality and Social Psychology, 91(4), 780-795.
Brennan, G. (2005). Developing a dynamic school culture: The role of the school principal. Masters thesis, University of Calgary.

Brutus, S., Fleenor, J., \& Tisak, J. (1999). Exploring the link between rating congruence and managerial effectiveness, Canadian Journal of Administrative Sciences, 16(4), 308-322.

Buono, A., \& Bowditch, J. (1989). The human side of mergers and acquisitions. San Francisco: Jossey-Bass Publishers.

Carlopio, J., Andrewartha, G., \& Armstrong, H. (2005). Developing Management Skills: A comprehensive guide for leaders, 3rd edn. Australia: Pearson Education.

Chambers, J.R., \& Windschitl, P.D. (2004). Biases in social comparative judgements: The role of non-motivated factors in above-average and comparative-optimism effects. Psychological Bulletin, 130, 813-838.

Church, A.H. (1997). Managerial self-awareness in high performing individuals in organizations. Journal of Applied Psychology, 82(2), 281-292.

CHE. (2004). The Governance of Mergers in South African Higher Education. Pretoria: The Council on Higher Education.

Chen, X., Ender, P., Mitchell, M. and Wells, C. (2003). Regression with SPSS. Retrieved July 28,2010 , from http://www.ats.ucla.edu/stat/spss/webbooks/reg/default. $\mathrm{htm}$

Detweiler-Bedell, B., Detweiler-Bedell, J.B., \& Salovey, P. (2006). Mood-congruent perceptions of success depend on self-other framing. Cognition and Emotion, 20(2), 196-216.

Department of Education, South Africa (2002). The Transformation and Reconstruction of the Higher Education System of Education. Retrieved May 21, 2010, from http://education.pwv.gov.za/Policies\%20and\%20Reports/2002_Reports/he/ transrestructuring.htm

Dulewicz, V., \& Higgs, M. (2005). Assessing leadership styles and organisational context. Journal of Managerial Psychology, 20(2), 105-123.

Duval, T.S., \& Silvia, P.J. (2002). Self-awareness, probability of improvement, and the self-serving bias, Journal of Personality and Social Psychology, 82(1), 49-61.

Fleenor, J.W., McCauley, C.D., \& Brutus, S. (1996). Self-other rating agreement and leader effectiveness. Leadership Quarterly, 7(4), 487-506.

Fletcher, C. (1997). Self-awareness - a neglected attribute in selection and assessment? International Journal of Selection and Assessment. 5(3), 183-187.

Fletcher, C., \& Baldray, C. (2000). A study of individual differences and self-awareness in the context of multi-source feedback. Journal of Occupational and Organizational Psychology, 73, 303-319.

Fletcher, C., \& Bailey, C. (2003). Assessing self-awareness: some issues and methods. Journal of Managerial Psychology, 18(5), 395-404.

Garson, G.D. (2010). Reliability Analysis North Carolina Sate University. Public Administration Program. http://faculty.chass.ncsu.edu/garson/PA765/reliab. htm\#alpha

Goleman, D. (1998). What makes a leader? Harvard Business Review, 76(6), 93-103.

Godshalk, V.M., \& Sosik, J.J. (2000). Does mentor-protégé agreement on mentor leadership behaviour influence the quality of a mentoring relationship? Group \& Organization management, 25, 291-317.

Hargreaves, A., \& Fink, D. (2003). The seven principles of sustainable leadership. International Centre for Educational Change, Ontario Institute for Studies in Education, University of Toronto.

Harris, A., Day, C., Hopkins, D., Hadfield, M., Hargreaves, A., \& Chapman, C. (2003). Effective leadership for school improvement. New York and London: Routledge6.9Bass.

Kouzes, J.M., \& Posner, B.Z. (1988). The leadership challenge. San Francisco: JosseyBass.

Kouzes, J.M., \& Posner, B.Z. (1995). Development and validation of Leadership Practices Inventory. Educational and Psychological Measurement 48, 483-496.

Kouzes, J.M., \& Posner, B.Z. (2001). The Leadership Practices Inventory (LPI). Facilitator's Guide, 2nd edn. San Francisco: Jossey-Bass/Pfeiffer.

Krishnan, V.R. (2003). Power and moral leadership: role of self-other agreement. Leadership and Organization Development Journal, 24(6), 345-351.

London, M. (2002). Leadership Development: Paths to self-insight and professional growth. Mahwah, New Jersey: Lawrence Erlbaum Associates.

Maree, J.G., \& Eiselen, R.J. (2004). The emotional intelligence profile of academics in a merger setting. Education and Urban Society, 36(4), 482-504.

Martin, A. (2005). The Changing Nature of Leadership. Retrieved September 5, 2008 , from http://www.ccl.org

Mayer, J.D., \& Geher, G. (1996). Emotional intelligence and the identification of emotion, Intelligence, 22, 89-113.

Mclagan, P. (2002). Change is everybody's business. San Francisco: Berrett-Koehler Publishers.

McCarthy, A.M., \& Garavan, T.N. (1999). Developing self-awareness in the managerial career development process: the value of 360-degree feedback and the MBTI. Journal of European Industrial Training, 23(9), 437-445.

McCroskey, S. (2008). The Leadership Challenge - for educational administrators, Academic Leadership, 6(3). Retrieved May 23, 2010, from http://www. academicleadership.org/emperical_research/468.shtml

Mouton, J., \& Marais, H.C. (1989). Metodologie van die Geesteswetenskalike: Basiese begrippe. Pretoria: Raad vir Geestewetenskaplike Navorsing.

Nisbett, R., \& Ross, L. (1980). Human inference: Strategies and short comings of social judgement. Englewood Cliffs, NJ: Prentice-Hall. 
Paterson, A. (2005). Changing the 'landscape' of learning: The future of blended learning provision in newly merged South African higher education systems. International Journal of Education and Development using ICT 1(2). Retrieved April International Journal of Education and Development using ICT, 1(2). Retrieved Ap
28,2010 , from http://ijedict.dec.uwi.edu/viewarticle.php?id=48\&layout=html

Randall, R., Ferguson, E., \& Patterson, F. (2000). Self-assessment accuracy and assessment centre decisions. Journal of Occupational and Organizational Psychology, 73, 443-459.

Seale, O. (2004). Rooting for management capacity in South African higher education Retrieved March 3, 2009, from http://www.hesda.org.uk/activities/vents/ sdev2004/workshop7.doc

Shaughnessy, J.J., \& Zechmeister, E.B. (1997). Research methods in psychology. (4th edn.). New York: McGraw-Hill.

Sosik, J., \& Megerian, L. (1999). Understanding leader emotional intelligence and performance - the role of self-other agreement on transformational leadership perceptions, Group and Organisation management, 24(3), 367-390.

Sosik, J.J., (2001). Self-Other agreement on charismatic leadership. Group and Organization Management, 26(4), 484-511.

Souba, W.W. (2006). The inward journey of leadership. Journal of surgical research, $131,159-167$

Strauss, J.P. (2005). Multi-source perspectives of self-esteem, performance ratings, and source agreement. Journal of Managerial Psychology, 20(6), 462-482.

Tekleab, A.G., Sims, H.P., Yun, S., Tesluk, P.E., \& Cox, J. (2008). Are we on the same page? Effects of self-awareness of empowering and transformational leadership. Journal of Leadership \& Organizational Studies, 14(3), 185-201. doi:10.1177/1071791907311069.
Van Ameijde, J.D.J., Nelson, P.C., Billsberry, J., \& Van Meurs, N. (2009). Improving leadership in Higher Education Institutions: a distributed perspective. Higher Education, doi:10.1007/s10734-009-9224-y.

Van Velsor, E., Taylor, S., \& Leslie, J.B. (1993). An examination of the relationships among self-perception accuracy, self-awareness, gender and leader effectiveness. Human Resource Management, 32(2-3), 249-263.

Van Velsor, E. \& McCauley, C.D. (2004). Our view of leadership development. In C.D. MacCauley and E. Van Velsor (Eds.), Handbook of leadership development. (2nd edn). San Francisco: Jossey-Bass.

Van Velsor, E., Taylor, S., \& Leslie, J.B. (2009). An examination of the relationships among self-perception accuracy, self-awareness, gender, and leadership effectiveness. Human Resource Management, 32(2-3), 249-263.

Vinger, G. (2008). The behaviour-oriented organisational change models and large scale organisational change: A case study of the South African Higher Education Transformation. The International Journal of Learning, 5(8), 195-204.

Yammarino, F., \& Atwater, L. (1993), Understanding self-perception accuracy: implications for human resource management, Human Resource Management 32(2), 231-47. doi:10.1002/hrm.3930320204

Yammarino, F.J., \& Atwater, L.E. (1997). Do managers see themselves as others see them? Implications for self-other rating agreement for human resources management. Organizational Dynamics, 25(4), 35-44.

Young, M., \& Dulewicz, V. (2007). Relationship between emotional and congruen self-awareness and performance in the British Royal Navy, Journal of Managerial Psychology, 22(5), 465-478.

Zaccaro, S. J., Kemp, C., \& Bader, P. (2004). Leader traits and attributes. In J. Antonakis, A.T. Cainciolo \& R.J. Sternberg (Eds.), The nature of leadership (pp. 101-124), Thousand Oaks: Sage Publications. 